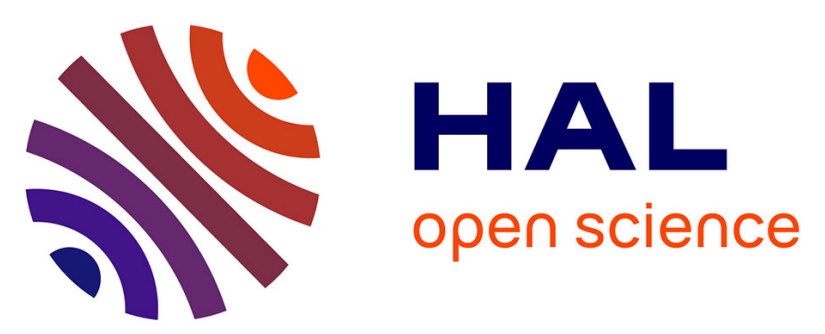

\title{
A more reliable DSC-based methodology to study crystallization kinetics: Application to poly(ether ketone ketone) (PEKK) copolymers
}

Tanguy Choupin, Bruno Fayolle, Gilles Régnier, Christophe Paris, Jacques

Cinquin, Benoît Brulé

\section{To cite this version:}

Tanguy Choupin, Bruno Fayolle, Gilles Régnier, Christophe Paris, Jacques Cinquin, et al.. A more reliable DSC-based methodology to study crystallization kinetics: Application to poly(ether ketone ketone) (PEKK) copolymers. Polymer, 2018, 155, pp.109-115. 10.1016/j.polymer.2018.08.060 . hal02292416

\section{HAL Id: hal-02292416 \\ https://hal.science/hal-02292416}

Submitted on 19 Sep 2019

HAL is a multi-disciplinary open access archive for the deposit and dissemination of scientific research documents, whether they are published or not. The documents may come from teaching and research institutions in France or abroad, or from public or private research centers.
L'archive ouverte pluridisciplinaire $\mathbf{H A L}$, est destinée au dépôt et à la diffusion de documents scientifiques de niveau recherche, publiés ou non, émanant des établissements d'enseignement et de recherche français ou étrangers, des laboratoires publics ou privés. 


\title{
A more reliable DSC-based methodology to study crystallization kinetics: Application to poly(ether ketone ketone) (PEKK) copolymers
}

\author{
Tanguy Choupin ${ }^{\mathrm{a}, \mathrm{b}}$, Bruno Fayolle ${ }^{\mathrm{a}, *}$, Gilles Régnier ${ }^{\mathrm{a}}$, Christophe Paris ${ }^{\mathrm{b}}$, Jacques Cinquin ${ }^{\mathrm{b}}$, \\ Benoît Bruléc \\ a PIMM, ENSAM, CNRS, CNAM, 151 boulevard de l'Hôpital, 75013, Paris, France \\ ${ }^{\mathrm{b}}$ Departement of Composites Materials, Airbus Group Innovations, 12 rue Pasteur, 92150, Suresnes, France \\ c Arkema, Cerdato, Route du Rilsan, 27470, Serquigny, France
}

\section{H I G H L I G H T S}

- Method is based on derivative expression for crystallization Hillier model.

- Model fitting directly on the crystallization heat flux measured by DSC.

- The method avoids the extrapolation of the crystallization peak beginning.

- PEKK Crystallization kinetic modeling including primary and secondary crystallization.

A R T I C L E IN F O

Keywords:

Poly(ether ketone ketone)

Thermal analysis

Crystallization kinetic modeling

\begin{abstract}
A B S T R A C T
To quantify the isothermal crystallization kinetics of poly(ether ketone ketone) (PEKK), the integration of the crystallization peak measured using differential scanning calorimetry is rendered difficult due to the thermal transient effects at the start of enthalpy recording. The different attempts to extrapolate this peak beginning often lead to false values of the Avrami exponent. A new crystallization kinetic assessment method is established here based on the derivative of the Hillier crystallization kinetic model. This method consists of directly fitting the transformation rate to the heat flow of the experimental crystallization, thus avoiding the extrapolation of the crystallization peak beginning. This method is successfully applied to two different PEKK grades with different crystallization kinetics. The identified crystallization parameters are modelled as a function of the crystallization temperature, and based on these modeling results, time-temperature-transformation diagrams of crystallinity were built to provide a useful tool for PEKK processing.
\end{abstract}

\section{Introduction}

High-performance poly(ether ketone ketone) (PEKK) thermoplastics are currently studied with great interest by the aeronautic industry as a matrix for carbon-fibre reinforced structural parts. In fact, PEKK composites can be consolidated out of autoclave, while they have lower processing temperatures than poly(ether ether ketone) (PEEK) composites. The final mechanical performances of composite parts are closely linked to their processing. Depending on the thermal processing cycle, the matrix properties as well as the interaction between the matrix and carbon fibres are modified. During the manufacturing of PEKK composite parts, the composite is first heated above the matrix melting temperature to decrease the viscosity of the matrix in order to evacuate all porosity under pressure. This step is known as consolidation. The composite part is then cooled to room temperature. During this step, the matrix may crystallize with a different crystallinity ratio depending on the cooling conditions that directly impact the final mechanical performances of the composite part [1-6]. For this reason, PEKK crystallization kinetics should be controlled in order to optimize the processing parameters in terms of the mechanical performances and processing times of the composite parts.

The crystallization mechanisms of PEKK copolymers have been studied by different authors [7-10] who have shown that similarly to PEEK, PEKK copolymers crystallize with two different crystallization processes, namely a primary crystallization that appears at the early stage of crystallization and a secondary crystallization corresponding to the enhancement of crystallization with the growth of a crystalline structure within lamellae [7]. This subsidiary crystallization should be

\footnotetext{
* Corresponding author.

E-mail address: bruno.fayolle@ensam.eu (B. Fayolle).
} 
taken into account in the crystallization kinetic model. Among the different crystallization kinetic models that consider this two-step crystallization, it was previously argued [10] that Hillier [11] proposed a good model with secondary crystallization kinetics directly dependant on the primary crystallized volume. Hsiao et al. [8] proposed an extension of this model by considering that the Avrami exponent of secondary crystallization $n_{2}$ could have values other than 1 ; the total relative crystallinity $\alpha(t)$ thus evolves as:

$\alpha(t)=w_{1} \alpha_{1}(t)+w_{2} \alpha_{2}(t)$

with the respective primary and secondary crystallization expressions:

$\alpha_{1}(t)=1-\exp \left(-K_{1} t^{n_{1}}\right)$

$\alpha_{2}(t)=K_{2} n_{2} \int_{0}^{t}\left[1-\exp \left(-K_{1} \theta^{n_{1}}\right)\right](t-\theta)^{n_{2}-1} \exp \left[-K_{2}(t-\theta)^{n_{2}}\right] d \theta$

where $n_{1}$ and $n_{2}$ correspond to the Avrami exponents, $\mathrm{K}_{1}$ and $\mathrm{K}_{2}$ to the crystallization rate constants, and $\mathrm{w}_{1}$ and $\mathrm{w}_{2}$ to the weight factor for the primary and the secondary crystallization, respectively. These weight factor values provide the relative importance between both crystallizations. At any time, we have $\mathrm{w}_{1}+\mathrm{w}_{2}=1$. For an infinite time, the total relative crystallinity is the unity that corresponds to the Avrami model hypotheses [12].

To identify the crystallization kinetic parameters, the Hillier model has to be fitted to the relative crystallinity calculated from the integration of crystallization heat flows measured using differential scanning calorimetry (DSC):

$\alpha(t)=\frac{\int_{0}^{t} Q(t)}{\int_{0}^{t_{\infty}} Q(t)} d t$

where $Q(t)$ is the heat flow measured at time $t$, and $t_{\infty}$ is the time when the polymer is fully crystallized.

As shown in the literature for other polymers [8,13-15], the integration of the PEKK crystallization peak is rendered difficult due to the truncation of the crystallization peak beginning, which has been attributed to instrumental thermal inertia when switching from the cooling to the isothermal step (Fig. 1). This phenomenon is more significant when the isothermal crystallization temperature decreases or the polymer has faster crystallization kinetics.

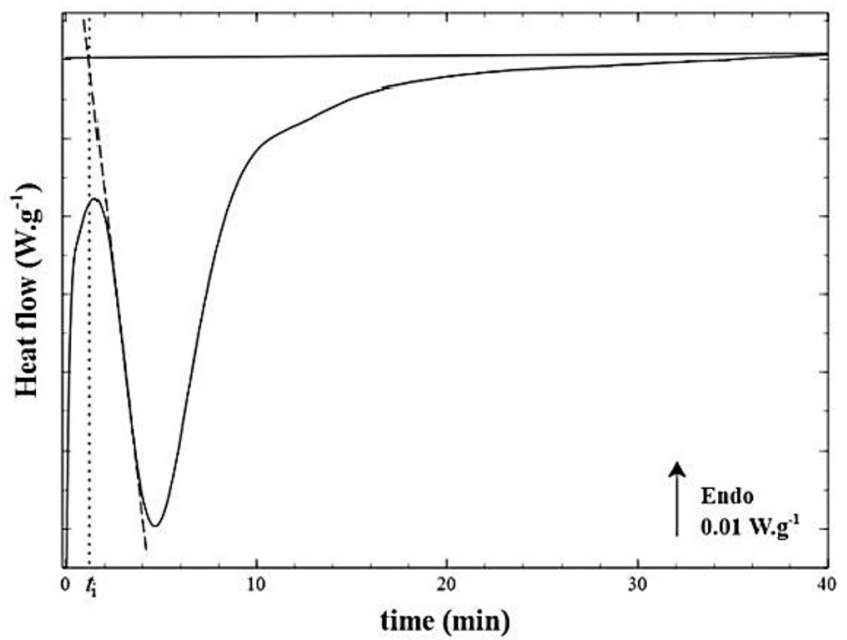

Fig. 1. Differential scanning calorimetry thermogram of poly(ether ketone ketone) 6002 crystallized from the melt during isothermal crystallization at $230^{\circ} \mathrm{C}$ with a linear extrapolation of the crystallization peak beginning (dashed line) inducing a crystallization induction time $t_{i}$ (dotted line).
In a previous article [10], we applied the usual method by extrapolating the beginning of the crystallization peak with a straight line (dashed line in Fig. 1) until the base line. However, this method implied the introduction of a crystallization induction time, which is not consistent with overall crystallization kinetic theories. Secondly, the Avrami exponent in this method was found to be close to 2 , which is associated with two-dimensional crystallization growth according to the Avrami theory if we consider instantaneous nucleation. However, this value of 2 is not consistent with the spherulite entities detected by microscopic observations as reported in the literature $[7,10]$.

This paper aimed to propose a new methodology to quantify the isothermal crystallization kinetics of PEKK without extrapolating the crystallization peak beginning. We show that this extrapolation could lead to physically inconsistent values for the Avrami exponent in terms of crystalline morphologies. Indeed, microscopic observations of quiescent crystallization put in evidence an instantaneous nucleation and a spherulitic growth corresponding to an Avrami exponent equal to 3. This new method will be applied to two PEKK copolymers with different crystallization kinetics, namely PEKK 6002 and 7002, to identify their crystallization kinetic parameters. Let us recall here that the proposed kinetic modeling can be applied only for some processing conditions in which strain (elongation or shear) rate during the crystallization can be neglected such as additive manufacturing or welding processes. Indeed, high strain rate conditions mainly promote the nucleation mechanisms by increasing nuclei number [16]. Finally, TTT diagrams of the relative volume crystallinity will be built from the overall crystallization kinetic modeling.

\section{Experimental}

\subsection{Materials}

The PEKK homopolymer is prepared using diphenyl ether (DPE) and terephthalic acid (T) (Fig. 2a). Terephthalic acid with para phenyl links can be substituted by isophthalic acid (I) with meta phenyl links (Fig. 2b) and form copolymers comprising two different isomers, namely terephthaloyl (Fig. 2a) and isophthaloyl isomers (Fig. 2b). These isomers can form two different diads: TT diads compounded with two terephthaloyl isomers and TI diads compounded with one terephthaloyl isomer and one isophthaloyl isomer.

The PEKK used in this study is provided by Arkema and referenced as PEKK 6002 and 7002. The ratios of terephthalic acid with para phenyl links and isophthalic acid with meta phenyl links are 60/40 and 70/30 for PEKK 6002 and 7002, respectively. The two PEKK grades have an average weight $\left(M_{w}\right)$ and number average molecular mass $\left(M_{n}\right)$ of about $70 \mathrm{~kg} . \mathrm{mol}^{-1}$ and $30 \mathrm{~kg} \mathrm{~mol}^{-1}$, respectively. Glass transition temperatures of both PEKKs are measured at around $155^{\circ} \mathrm{C}$, while the melting temperatures for PEKK 6002 and 7002 are $305^{\circ} \mathrm{C}$ and $332^{\circ} \mathrm{C}$, respectively, using DSC with a heating stage of $10^{\circ} \mathrm{C} / \mathrm{min}$.

\subsection{Differential scanning calorimetry (DSC)}

Isothermal crystallization analyses are carried out using TA Instruments Q2000 with granules of about 7-8 mg. All specimens are first heated at $10^{\circ} \mathrm{C} . \mathrm{min}^{-1}$ from room temperature to $360^{\circ} \mathrm{C}$ for PEKK 6002 and $380^{\circ} \mathrm{C}$ for PEKK 7002 for $5 \mathrm{~min}$. These temperatures are above the PEKK equilibrium melting temperatures $\left(\mathrm{T}_{\mathrm{m} 0}=340^{\circ} \mathrm{C}[7]\right)$ and erase the thermal history. Specimens are then cooled at $40{ }^{\circ} \mathrm{C} \cdot \mathrm{min}^{-1}$ to annealing temperatures. Annealing temperatures are maintained for $240 \mathrm{~min}$, and specimens are finally cooled to room temperature at $40^{\circ} \mathrm{C} \cdot \mathrm{min}^{-1}$. The chosen cooling and heating rates are high enough to ensure that the polymer does not crystallize before annealing, while the annealing time is long enough to allow the polymer to crystallize fully. For all specimens, a heat scan at $10^{\circ} \mathrm{C} \cdot \mathrm{min}^{-1}$ to $400^{\circ} \mathrm{C}$ is carried out after crystallization to measure the glass transition, melting temperature, and melting enthalpy induced by the crystallization cycle. 


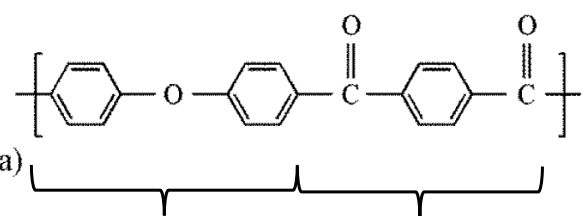

DPE

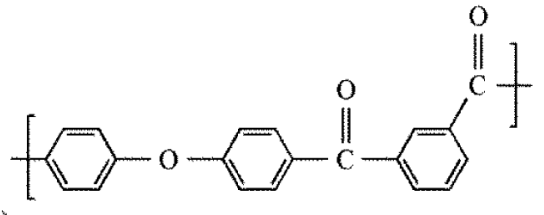

b)

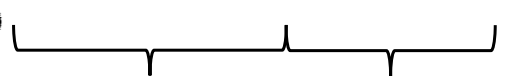

DPE

I

Fig. 2. Poly(ether ketone ketone) a) terephthaloyl and b) isophthaloyl isomers.

\section{Results and discussion}

\subsection{Derivative Hillier method}

This new identification method based on the Hillier model consists of directly fitting the crystallization heat flow measured by DSC without extrapolating the heat flux at low times and considering only reliable DSC measurements (Fig. 1). The fitting can be done using multi-nonlinear regression available in various numerical tools; we used the "fit" function of the Scilab development tool. Moreover, directly identifying the heat flux by multi-nonlinear regression allows the best baseline to be easily determined according to the model. By deriving Eq. (4), it can thus be written:

$\frac{d \alpha}{d t}=\frac{Q(t)}{\int_{0}^{t_{\infty}} Q(t) d t}=\frac{Q(t)}{\Delta H_{c}}=\frac{Q(t)}{\Delta H_{m}}$

where $\alpha$ is the relative crystallinity, $Q(t)$ the DSC heat flux per mass unit, $\Delta H_{c}$ the crystallization enthalpy, and $\Delta H_{m}$ the melting enthalpy after crystallization, which was obtained by rapid heating to hinder any fusion or recrystallization process.

The derivative of the primary crystallization kinetic equation (Eq. (2)) can be expressed as follows:

$\frac{d \alpha_{1}}{d t}=K_{1} n_{1} t^{n_{1}-1} \exp \left(-K_{1} t^{n_{1}}\right)$

It can be observed that at time close to 0 , the derivative of the primary crystallization kinetic equation (Eq. (6)) tends toward:

$\frac{d \alpha_{1}}{d t} \propto K_{1} n_{1} t^{n_{1-1}}$

Thus, the choice or imposition of curve type to extrapolate the DSC signal will have an influence on the value of the Avrami exponent. If $n_{1}$ is equal to equal to 2 , for example, the expression of the derivative of the primary crystallization corresponds to the equation of a linear curve with a slope equal to $\mathrm{K}_{1} \mathrm{n}_{1}$. This observation is very interesting, because if we assume that the primary crystallization is the main physical phenomenon during the beginning of crystallization, then our extrapolation of the DSC signal by a linear curve primarily explains the Avrami exponent value close to 2 for the primary crystallization found in the first approach [10]. However, this value is inconsistent with microscopic observations previously reported in Refs. [7] and [10]: it can be observed that all crystallite entities have the same size, so instantaneous crystallization can be easily assumed. Moreover, it is difficult to imagine that crystalline entities are not spherulites, and thus according to the Avrami theory [12], the primary crystallization Avrami exponents $n_{1}$ could be logically fixed to a value of 3 .

The secondary crystallization rate has the following form:

$\alpha_{2}(t)=\int_{0}^{t} f(\theta, t) d \theta$

Its derivative can be calculated as follows: $\frac{d \alpha_{2}}{d t}=f(t, t)+\int_{0}^{t} \frac{\partial f(\theta, t)}{\partial t} d \theta$

Consequently, the derivative of the secondary crystallization kinetic equation (Eq. (3)) calculated using Eq. (9) can be expressed by:

$$
\begin{aligned}
& \frac{d \alpha_{2}}{d t}=K_{2} n_{2}\left[1-\exp \left(-K_{1} t^{n_{1}}\right)\right] \\
& +K_{2} n_{2} \int_{0}^{t}\left[1-\exp \left(-K_{1} \theta^{n_{1}}\right)\right] \exp \left[-K_{2}(t-\theta)^{n_{2}}\right]\left\{\left(n_{2}-1\right)(t-\theta)^{n_{2}-2}\right. \\
& \left.\quad-K_{2} n_{2}(t-\theta)^{2 n_{2}-2}\right\} d \theta
\end{aligned}
$$

The fitting of the derivative Hillier model (Eq. (6) and (10)) to the heat flow measured by DSC and divided by the melting enthalpy $\Delta \mathrm{H}_{\mathrm{m}}$ (Eq. (5)) for the isothermal crystallization of PEKK 6002 at $230{ }^{\circ} \mathrm{C}$ and $200{ }^{\circ} \mathrm{C}$ is presented in Fig. 3. Heat flux for the primary (Eq. (6)) and secondary crystallization mechanisms (Eq. (10)) based on the derivative Hillier model fitting are also plotted. Assuming that the crystallization process begins at the same time as the isothermal stage, it can be observed that no induction times are found for this approach compared to our previous work [10].

It is noteworthy that the best fits shown in Fig. 3 for the derivative Hillier model determined with non-linear regression fitting are obtained with a value of 1 for the secondary crystallization Avrami exponent $\left(\mathrm{n}_{2}=1\right)$. In this case, Eq. (10) can be simplified as follows:

$\frac{d \alpha_{2}}{d t}=K_{2}\left[1-\exp \left(-K_{1} t^{n_{1}}\right)\right]-K_{2}^{2} \int_{0}^{t}\left[1-\exp \left(-K_{1} \theta^{n_{1}}\right)\right] \exp \left[-K_{2}(t-\theta)\right] d \theta$

As a result, the derivative of the Hillier crystallization kinetic model can be expressed by:

$$
\begin{aligned}
\frac{d \alpha}{d t}= & w_{1} K_{1} n_{1} t^{n_{1}-1} \exp \left(-K_{1} t^{n_{1}}\right) \\
& +w_{2} K_{2}\left[1-\exp \left(-K_{1} t^{n_{1}}\right)\right]-w_{2} K_{2}^{2} \int_{0}^{t}\left[1-\exp \left(-K_{1} \theta^{n_{1}}\right)\right] \exp \left[-K_{2}(t-\theta)\right] d \theta
\end{aligned}
$$

Finally, the simplified expression of the derivative Hillier model is, according to our knowledge, given below for the first time:

$\frac{d \alpha}{d t}=w_{1} K_{1} n_{1} t^{n_{1}-1}\left(1-\alpha_{1}\right)+w_{2} K_{2}\left(\alpha_{1}-\alpha_{2}\right)$

Although this last relation is not useful for fitting, it allows us to understand well the physical meaning of the Hillier model by showing the dependence of the secondary crystallization on the primary crystallization. Nevertheless, this formulation is easily implementable in numerical models.

Finally, we can observe in Fig. 3 that the overall derivative Hillier model fits well with the heat flow and allows us to build the beginning of the crystallization peak truncated by DSC. Besides, we can witnessed the first part of the derivative Hillier model is first associated with the primary crystallization, which shows that the very beginning of the crystallization process corresponds only to the growth of the primary 

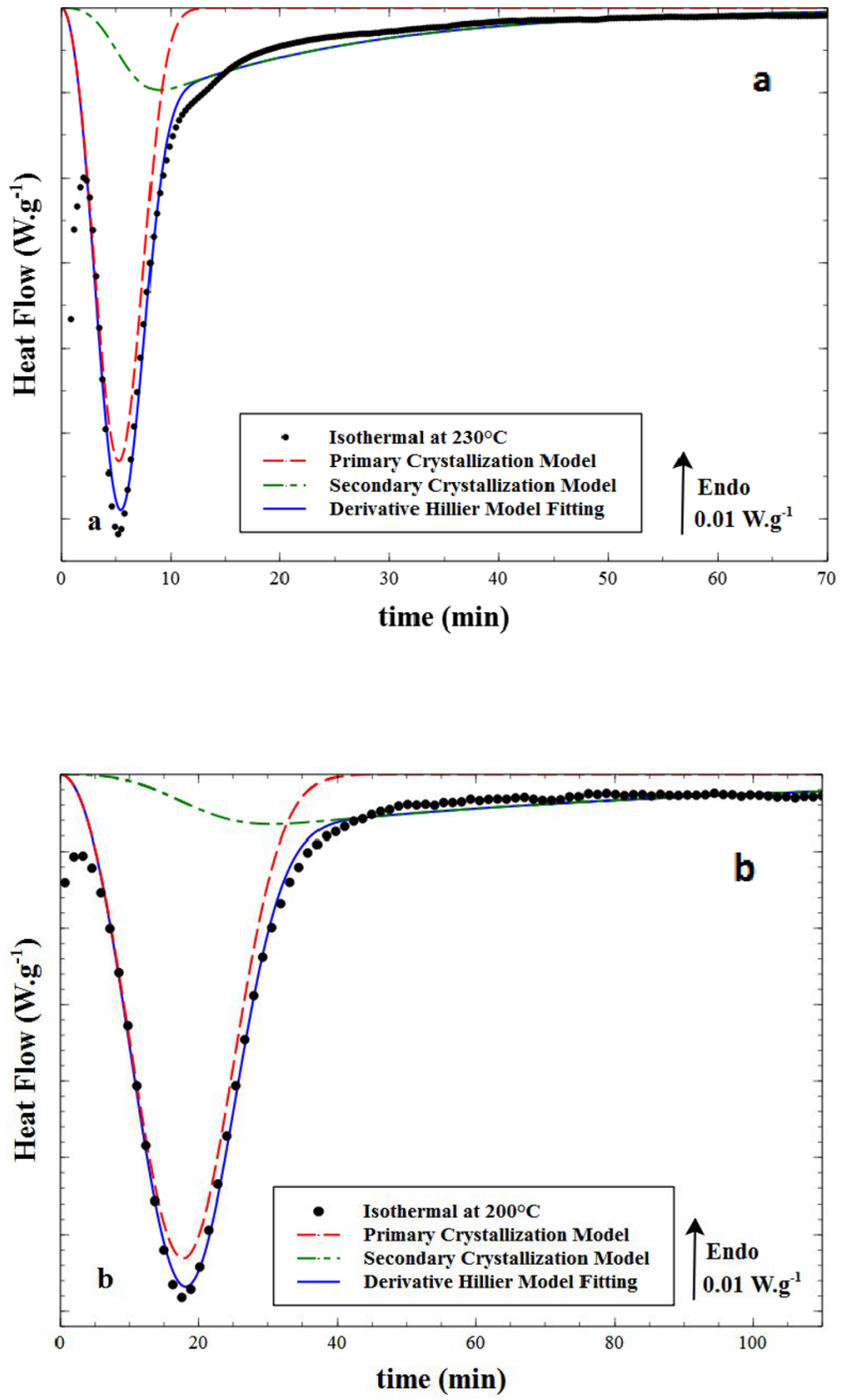

Fig. 3. Differential scanning calorimetry thermograms of neat poly(ether ketone ketone) 6002 crystallized from the melt at (a) $230^{\circ} \mathrm{C}$ and(b) $200^{\circ} \mathrm{C}$ with the fitting of the derivative Hillier model (solid line) and primary (dash curve) and secondary crystallization (dash-dot curve) modeling.

crystallization. This is then followed by the secondary crystallization growth in relation to the enhancement of the first crystallization stage.

The crystallization kinetics of PEKK 7002 is also studied to validate the derivative Hillier model on a PEKK copolymer that crystallizes faster than PEKK 6002. Fig. 4 presents the result of the fitting of the derivative Hillier model (Eqs. (6) and (10)) with the heat flow measured by DSC for PEKK 7002 crystallized at $250{ }^{\circ} \mathrm{C}$ compared to PEKK 6002 crystallized at $230^{\circ} \mathrm{C}$. It is noteworthy the crystallization kinetic for PEKK 6002 is not complete after $13 \mathrm{~min}$, especially the secondary one which is more visible in Fig. 3a. The same primary crystallization Avrami exponent $\left(n_{1}=3\right)$ as PEKK 6002 is chosen for PEKK 7002 regarding the optical microscopic observations. The same secondary crystallization Avrami exponent $\left(\mathrm{n}_{2}=1\right)$ as PEKK 6002 is also used corresponding to the best fit of the derivative Hillier model. The chosen crystallization temperatures correspond to the fastest temperatures for the crystallization kinetics of PEKK 6002 and 7002. It can be observed that even if the crystallization peak for PEKK 7002 is very narrow compared to PEKK 6002 (Fig. 4), the derivative Hillier model fits well with the experiments and allows us to rebuild the crystallization peak beginning.

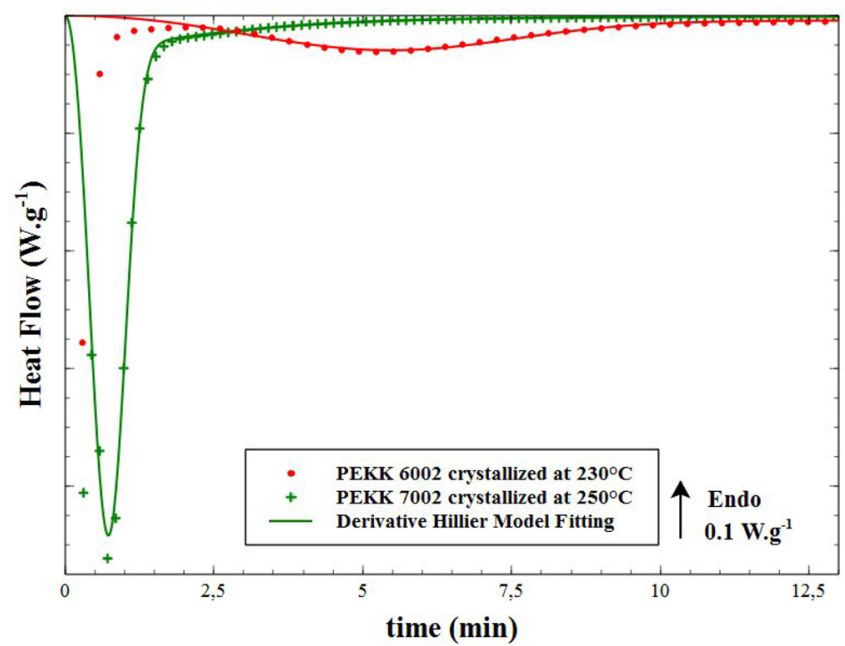

Fig. 4. Comparison of the fitting of the derivative Hillier model for neat poly (ether ketone ketone) (PEKK) 6002 and 7002.

\subsection{Hillier parameter modeling}

Following the general approach reported in the literature for nucleation and crystallization growth, the crystallization rate constants $\left(\mathrm{K}_{1}\right.$ and $\mathrm{K}_{2}$ ) can be expressed as a function of the initial number of potential nuclei $\left(\mathrm{N}_{0}\right)$ and crystal growth rate $(\mathrm{G})$ depending on the crystallization dimensionality and nucleation mode. For primary crystallization, shown to have three-dimensional crystallization growth with an instantaneous nucleation, the crystallization rate constant can be written as:

$K_{1}=\frac{4}{3} \pi N_{01} G_{1}^{3}$

where $\mathrm{N}_{01}$ is the initial number of potential nuclei and $\mathrm{G}_{1}$ the crystallization growth rate for primary crystallization.

For secondary crystallization, shown to have one-dimensional crystallization growth with instantaneous nucleation, the crystallization rate constant can be written as:

$K_{2}=N_{02} G_{2}$

where $\mathrm{N}_{02}$ is the initial number of potential nuclei and $\mathrm{G}_{2}$ the crystallization growth rate for secondary crystallization.

According to the Hoffmann and Lauritzen theory [17-19], crystal growth can be expressed by:

$G_{i}(T)=G_{0 i} \exp \left(-\frac{U^{*}}{R\left(T-T_{\infty}\right)}\right) \exp \left(-\frac{K_{g i}}{T \Delta T f}\right)$

where $\mathrm{G}_{0 \mathrm{i}}$ is a pre-exponential factor independent of temperature. The first exponential term contains the contribution of the diffusion process to the growth rate, where $\mathrm{U}^{*}$ is the activation energy of the molecular transferring through the melt crystal interface, $\mathrm{T}_{\infty}$ is the temperature below which diffusion stops $\left(\mathrm{T}_{\infty}=\mathrm{T}_{\mathrm{g}}-30 \mathrm{~K}\right)$ with $\mathrm{T}_{\mathrm{g}}=155^{\circ} \mathrm{C}$, and $\mathrm{R}$ is the gas constant.

The second exponential term is the contribution of the nucleation process, where Kgi is the activation energy of nucleation for a crystal of critical size, $\Delta \mathrm{T}$ is the degree of supercooling $\left(\Delta \mathrm{T}=\mathrm{T}_{\mathrm{m} 0}-\mathrm{T}\right)$ with $\mathrm{T}_{\mathrm{m} 0}$ as the equilibrium melting temperature, and $\mathrm{f}$ is a correction coefficient for the temperature dependence of the melting enthalpy $(f=2 \mathrm{~T} /$ $(T m 0+T)$ ). The index $i$ for $\mathrm{G}_{\mathrm{i}}, \mathrm{G}_{\mathrm{Oi}}$, and $\mathrm{K}_{\mathrm{gi}}$ is equal to 1 for primary crystallization and 2 for secondary crystallization.

Finally, the primary crystallization rate constant can be written as:

$K_{1}(T)=K_{01} \exp \left(-\frac{3 U^{*}}{R\left(T-T_{\infty}\right)}\right) \exp \left(-\frac{3 K_{\mathrm{g} 1}}{T \Delta T f}\right)$ 

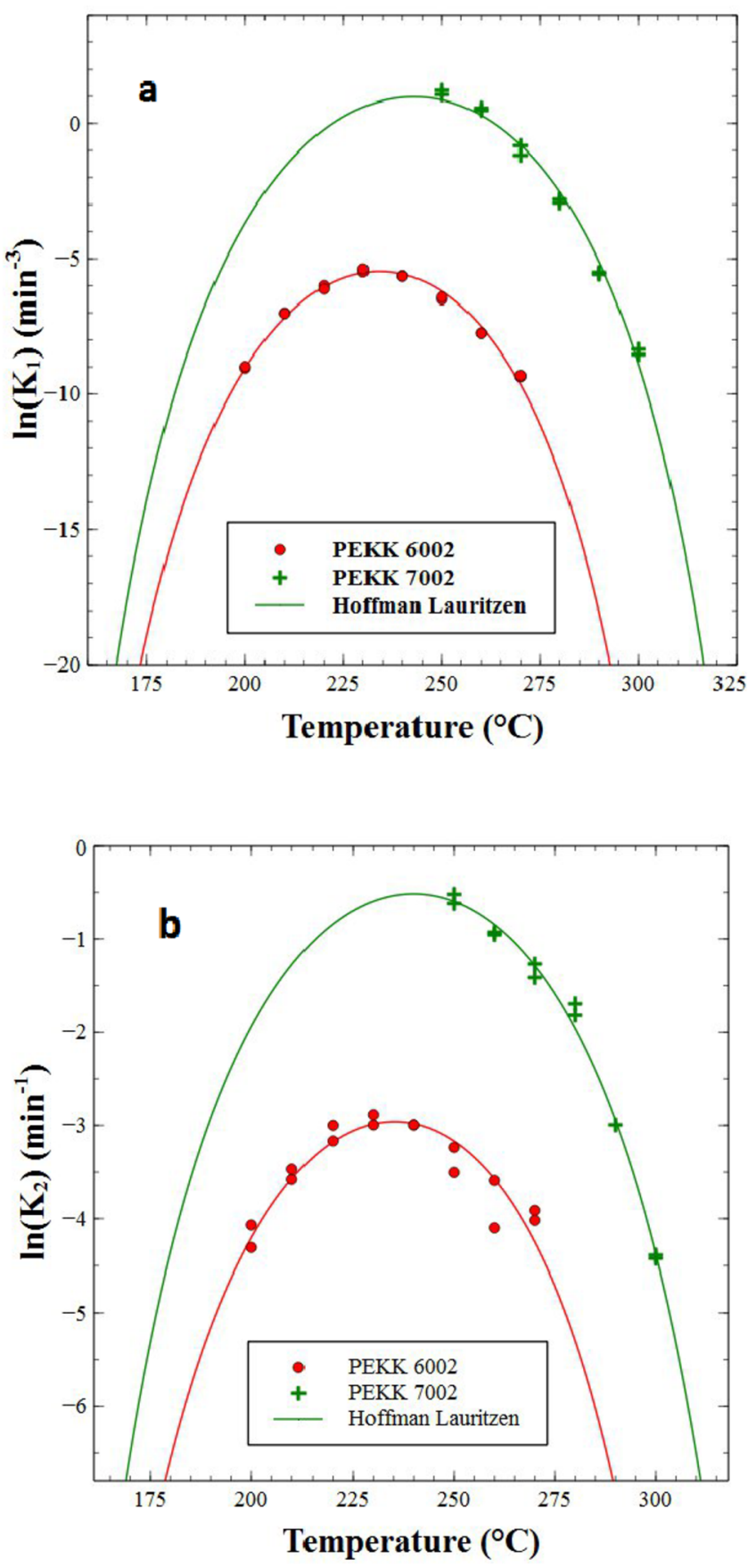

Fig. 5. Logarithmic plot of the (a) primary and (b) secondary crystallization rate constants versus temperature for neat poly(ether ketone ketone) (PEKK) 6002 and 7002 isothermal crystallization from the melt using the Hoffman and Lauritzen model fitting.

And the secondary crystallization rate constant can be written as:

$K_{2}(T)=K_{02} \exp \left(-\frac{U^{*}}{R\left(T-T_{\infty}\right)}\right) \exp \left(-\frac{K_{g 2}}{T \Delta T f}\right)$

with the pre-exponential factors $K_{01}=\frac{4}{3} \pi N_{01} G_{01}^{3}$ and $K_{02}=N_{02} G_{02}$ independent of temperature.

Regarding the evolution of the primary crystallization weight factor $\mathrm{w}_{1}$ with the crystallization temperature (Fig. 6), it was chosen to model $\mathrm{w}_{1}$ by a linear equation:

$w_{1}(T)=a_{1} T+b_{1}$

where $a_{1}$ and $b_{1}$ are two constants independent of temperature.

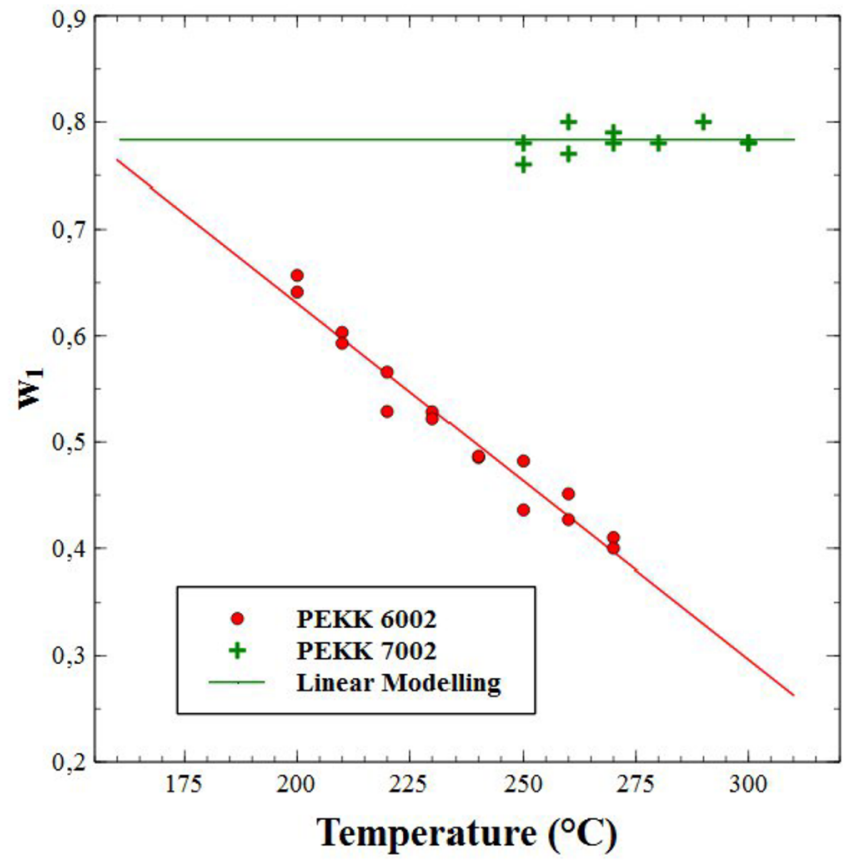

Fig. 6. Weight factor of the primary crystallization versus temperature isothermal crystallization for poly(ether ketone ketone) (PEKK) 6002 and 7002 from the melt using the linear model fitting.

The comparison of the logarithm of the Hillier parameters $\mathrm{K}_{1}$ and $\mathrm{K}_{2}$ for PEKK 6002 and 7002 is plotted in Fig. 5 and fitted with the Hoffman and Lauritzen model (Eqs. (16) and (17), respectively). Unlike PEKK 6002, it is not possible to carry out isothermal crystallization measurements over a large temperature range, but only until $260^{\circ} \mathrm{C}$. As PEKK 7002 crystallizes very quickly, below this temperature, the polymer crystallizes before the isothermal crystallization stage. A solution could be to use a flash DSC to reach the lower crystallization temperatures, as performed by Tardif et al. [15] for PEEK (although this tool implies very small samples that may not be representative of a voluminous crystallization process). Results for $\mathrm{K}_{0 \mathrm{i}}$ and $\mathrm{K}_{\mathrm{gi}}$ are presented in Table 1. As expected, we observed that both plots have typical bell shapes in accordance with the Hoffman and Lauritzen growth theory [18]. Crystallization kinetic parameters $\mathrm{K}_{1}$ and $\mathrm{K}_{2}$ are much higher for PEKK 7002 than PEKK 6002. Crystallization kinetics are the fastest around $240{ }^{\circ} \mathrm{C}$ for PEKK 6002 and $245^{\circ} \mathrm{C}$ for PEKK 7002 . Values of $\mathrm{K}_{\mathrm{gi}}$ are similar to those reported in the literature for other poly(aryl ether ketones) [20,21].

The primary crystallization weight factor $\left(\mathrm{w}_{1}\right)$ for PEKK 6002 and 7002 is plotted as a function of temperature in Fig. 6 with the fitting of the linear model (Eq. (18)). Results for $a_{1}$ and $b_{1}$ are presented in Table 1. We observed that for PEKK 6002, $\mathrm{w}_{1}$ decreases with temperature, knowing that $\mathrm{w}_{1}+\mathrm{w}_{2}=1$ (see eqs. (1)-(3)), it shows that the formation of the secondary crystallization is promoted by the low

Table 1

Parameters of the kinetic models for the crystallization rate constants $\left(\mathrm{K}_{1}\right.$ and $\mathrm{K}_{2}$ ) and the weight factor ( $\left.\mathrm{w}_{1}\right)$ for poly(ether ketone ketone) (PEKK) 6002 and 7002 crystallized from the melt.

\begin{tabular}{lll}
\hline Kinetic parameters & PEKK 6002 & PEKK 7002 \\
\hline $\mathrm{T}_{\mathrm{m} 0}\left({ }^{\circ} \mathrm{C}\right)$ & 340 & 360 \\
$\mathrm{~K}_{01}\left(\mathrm{~min}^{-3}\right)$ & $1.1 .10^{14}$ & $1.79 .10^{16}$ \\
$\mathrm{~K}_{02}\left(\mathrm{~min}^{-1}\right)$ & $1.1 .10^{4}$ & $2.6 .10^{5}$ \\
$\mathrm{~K}_{\mathrm{g} 1}\left(\mathrm{~K}^{2}\right)$ & $3.6 .10^{5}$ & $4.0 .10^{5}$ \\
$\mathrm{~K}_{\mathrm{g} 2}\left(\mathrm{~K}^{2}\right)$ & $3.5 .10^{5}$ & $4.4 .10^{5}$ \\
$\mathrm{U}^{*}\left(\mathrm{~J}^{\mathrm{mol}}{ }^{-1}\right)$ & $4.7 .10^{3}$ & $4.7 .10^{3}$ \\
$\mathrm{a}_{1}\left(\mathrm{~K}^{-1}\right)$ & $-3.3 .10^{-3}$ & 0 \\
$\mathrm{~b}_{1}$ & 2.2 & 0.78 \\
\hline
\end{tabular}



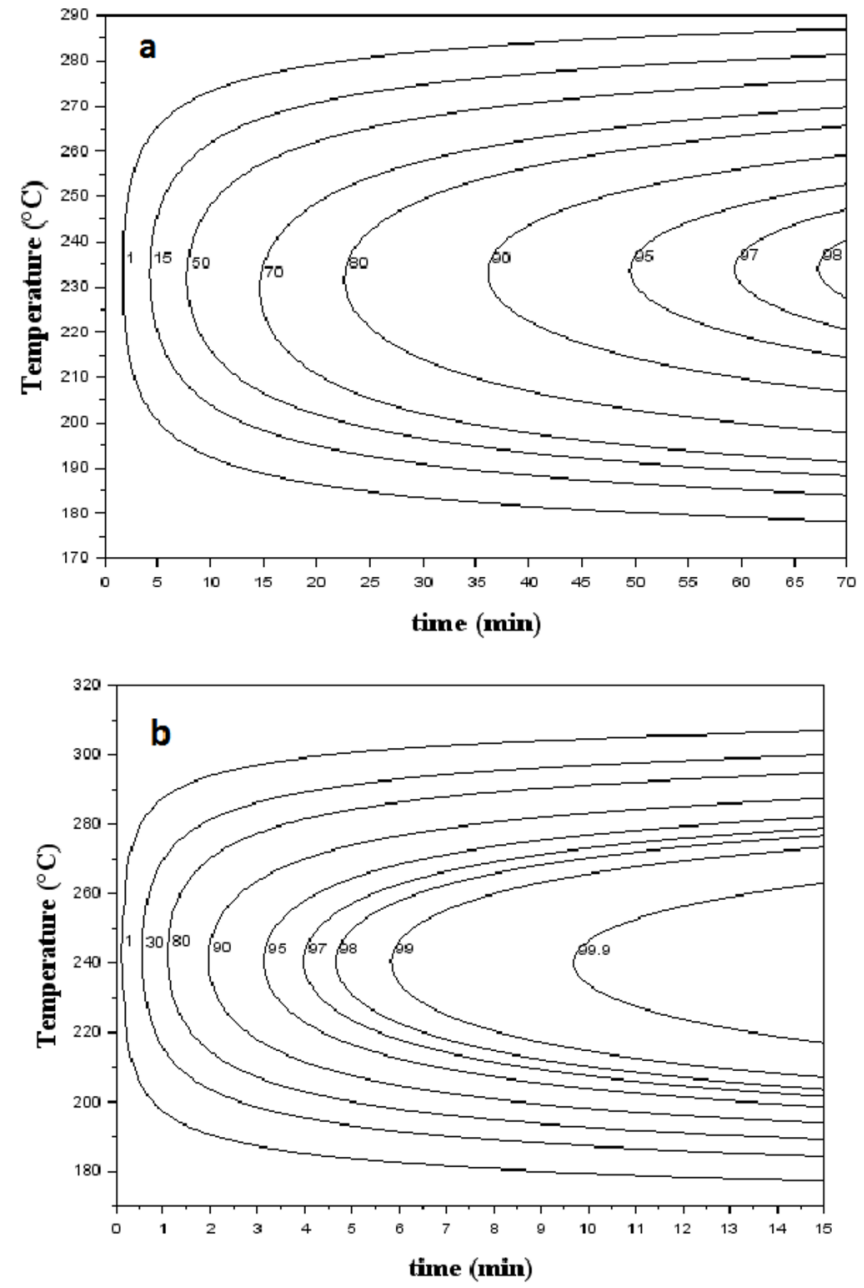

Fig. 7. Time-temperature-transformation diagram of the relative crystallinity of poly(ether ketone ketone) (PEKK) (a) 6002 (b) and7002 crystallized from the melt.

degree of supercooling. This observation is also reported by other authors $[9,22]$, with an increase in the first endothermic peak, which occurs $10^{\circ} \mathrm{C}$ above the annealing temperature attributed to the melting of the secondary crystallization. In fact, for high annealing temperatures, the diffusion process is very important, with a high mobility of chains allowing the crystalline phase to be enhanced. For PEKK 7002, $\mathrm{w}_{1}$ seems to be quasi-constant as a function of temperature with a value of around 0.78. PEKK 7002 wt factors are higher than for PEKK 6002, which could be attributed to a more organized crystallization process that leaves less room for the growth of secondary crystallization.

\subsection{Time-temperature-transformation (TTT) diagrams}

As the relative crystallinity of PEKK 6002 and 7002 depending on time can be determined for any temperatures with the modeling of the Hillier parameters, we built TTT diagrams of the relative volume fraction crystallinity for the overall crystallization for PEKK 6002 (Fig. 7a) and 7002 (Fig. 7b). This kind of representation allows the crystallinity of the material to be determined for any isothermal crystallization process as well as the corresponding crystallinity ratios of each crystallization mechanism. As expected, crystallization kinetics are fastest around $240{ }^{\circ} \mathrm{C}$ for PEKK 6002 and $245^{\circ} \mathrm{C}$ for PEKK 7002. The TTT diagrams show the very fast crystallization kinetics of PEKK 7002 compared to PEKK 6002. For example, it takes $10 \mathrm{~min}$ for PEKK 7002 to fully crystallize at $240{ }^{\circ} \mathrm{C}$, whereas only about $50 \%$ of PEKK 6002 crystallizes in the same conditions.

\section{Conclusion}

The modeling of PEKK crystallization kinetics proves difficult due to a significant secondary crystallization, which has to be taken into account in the process modeling. Furthermore, to typically assess the crystallization enthalpy based on the DSC thermogram, the integration of the crystallization heat flow implies an extrapolation of the beginning of isothermal crystallization stage. If the extrapolation is done using a straight line, this generally involves a truncation of the beginning of all isothermal crystallization peaks. As a result, this truncation leads to underestimating the crystallization enthalpy value, constraining the Avrami exponent to a value close to 2, and sometimes introducing an induction time to fit the data with overall crystallization kinetic modeling.

To solve this problem, we established a new methodology from the derivative of the Hillier isothermal crystallization kinetic model, which can be directly fitted on the crystallization heat flux measured by DSC. The Hillier model allows us to deconvolute the contribution of the primary and secondary crystallization processes. This approach has been successfully applied to PEKK 6002 and 7002 for isothermal crystallizations from the glassy state and from the melt between $200{ }^{\circ} \mathrm{C}$ and $300^{\circ} \mathrm{C}$. PEKK 7002 was shown to crystallize much faster than PEKK 6002 , with rapid crystallization kinetics around $245^{\circ} \mathrm{C}$. According to the linear modeling of the primary crystallization weight factor $\mathrm{w}_{1}$, the secondary mechanism was found to be enhanced for a low degree of supercooling due to the high diffusion process for PEKK 6002, whereas it was observed to be constant for PEKK 7002. Finally, the isothermal TTT diagrams for crystallinization built for PEKK 6002 and 7002 provide a useful tool for PEKK processing.

\section{Acknowledgments}

The authors wish to thank the Arkema Company for providing the PEKK materials. ANRT (CIFRE $\mathrm{N}^{\circ} 2014 / 0797$ ) is also gratefully acknowledged for financial support.

\section{References}

[1] M.F. Talbott, G.S. Springer, L.A. Berglund, The effects of crystallinity on the mechanical properties of PEEK polymer and graphite fiber reinforced PEEK, J. Compos. Mater. 21 (1987) 1056-1081, https://doi.org/10.1177/ 002199838702101104.

[2] P. Cebe, S.Y. Chung, S.-D. Hong, Effect of thermal history on mechanical properties of polyetheretherketone below the glass transition temperature, J. Appl. Polym. Sci. 33 (1987) 487-503, https://doi.org/10.1002/app.1987.070330217.

[3] A.J. Peacock, L. Mandelkern, The mechanical properties of random copolymers of ethylene: force-elongation relations, J. Polym. Sci., Part B: Polym. Phys. 28 (1990) 1917-1941, https://doi.org/10.1002/polb.1990.090281104.

[4] S.-L. Gao, J.-K. Kim, Cooling rate influences in carbon fibre/PEEK composites. Part 1. Crystallinity and interface adhesion, Compos. Part Appl. Sci. Manuf 31 (2000) 517-530, https://doi.org/10.1016/S1359-835X(00)00009-9.

[5] J. Diani, F. Bédoui, G. Régnier, On the relevance of the micromechanics approach for predicting the linear viscoelastic behavior of semi-crystalline poly(ethylene) terephtalates (PET), Mater. Sci. Eng. 475 (2008) 229-234, https://doi.org/10. 1016/j.msea.2007.05.002.

[6] A. Pawlak, A. Galeski, Plastic deformation of crystalline polymers: the role of cavitation and crystal plasticity, Macromolecules 38 (2005) 9688-9697, https://doi. org/10.1021/ma050842o.

[7] K.H. Gardner, B.S. Hsiao, R.R. Matheson, B.A. Wood, Structure, crystallization and morphology of poly (aryl ether ketone ketone), Polymer 33 (1992) 2483-2495, https://doi.org/10.1016/0032-3861(92)91128-O.

[8] B.S. Hsiao, I.Y. Chang, B.B. Sauer, Isothermal crystallization kinetics of poly(ether ketone ketone) and its carbon-fibre-reinforced composites, Polymer 32 (1991) 2799-2805, https://doi.org/10.1016/0032-3861(91)90111-U.

[9] L. Quiroga Cortés, N. Caussé, E. Dantras, A. Lonjon, C. Lacabanne, Morphology and dynamical mechanical properties of poly ether ketone ketone (PEKK) with meta phenyl links, J. Appl. Polym. Sci. 133 (2016) 1-10, https://doi.org/10.1002/app. 43396.

[10] T. Choupin, B. Fayolle, G. Régnier, C. Paris, J. Cinquin, B. Brulé, Isothermal crystallization kinetic modeling of poly(etherketoneketone) (PEKK) copolymer, Polymer 111 (2017) 73-82, https://doi.org/10.1016/j.polymer.2017.01.033.

[11] I.H. Hillier, Modified avrami equation for the bulk crystallization kinetics of spherulitic polymers, J. Polym. Sci. 3 (1965) 3067-3078, https://doi.org/10.1002/ pol.1965.100030902. 
[12] M. Avrami, Kinetics of phase change. I general theory, J. Chem. Phys. 7 (1939) 1103-1112, https://doi.org/10.1063/1.1750380.

[13] A. Jonas, R. Legras, Thermal stability and crystallization of poly(aryl ether ether ketone), Polymer 32 (1991) 2691-2706, https://doi.org/10.1016/0032-3861(91) 90095-Z.

[14] A.T. Lorenzo, M.L. Arnal, J. Albuerne, A.J. Müller, DSC isothermal polymer crystallization kinetics measurements and the use of the Avrami equation to fit the data: guidelines to avoid common problems, Polym. Test. 26 (2007) 222-231, https:// doi.org/10.1016/j.polymertesting.2006.10.005.

[15] X. Tardif, B. Pignon, N. Boyard, J.W.P. Schmelzer, V. Sobotka, D. Delaunay, C. Schick, Experimental study of crystallization of polyetheretherketone (PEEK) over a large temperature range using a nano-calorimeter, Polym. Test. 36 (2014) 10-19, https://doi.org/10.1016/j.polymertesting.2014.03.013.

[16] F. Bustos, P. Cassagnau, R. Fulchiron, Effect of molecular architecture on quiescent and shear-induced crystallization of polyethylene, J. Polym. Sci. B Polym. Phys. 44 (11) (2006) 1597-1607.

[17] D. Turnbull, J.C. Fisher, Rate of nucleation in condensed systems, J. Chem. Phys. 17
(1949) 71-73, https://doi.org/10.1063/1.1747055.

[18] J.D. Hoffman, J.I. Lauritzen, Crystallization of bulk polymers with chain folding: theory of growth of lamellar spherulites, J. Res. Natl. Bur. Stand. Sect. Phys. Chem. 65A (1961) 297, https://doi.org/10.6028/jres.065A.035.

[19] J.D. Hoffman, R.L. Miller, Kinetic of crystallization from the melt and chain folding in polyethylene fractions revisited: theory and experiment, Polymer 38 (1997) 3151-3212, https://doi.org/10.1016/S0032-3861(97)00071-2.

[20] T. Liu, Z. Mo, S. Wang, H. Zhang, Isothermal melt and cold crystallization kinetics of poly(aryl ether ether ketone ketone) (PEEKK), Eur. Polym. J. 33 (1997) 1405-1414, https://doi.org/10.1016/S0014-3057(97)00016-5.

[21] M.J. Jenkins, J.N. Hay, N.J. Terrill, Structure evolution in melt crystallised PEEK, Polymer 44 (2003) 6781-6787, https://doi.org/10.1016/S0032-3861(03)00749-3.

[22] M. Dasriaux, S. Castagnet, L. Thilly, L. Chocinski-Arnault, S.A.E. Boyer, Evolution of the amorphous fraction of PEEK during annealing at atmospheric and high pressure above the glass transition temperature, J. Appl. Polym. Sci. 130 (2013) 1148-1157, https://doi.org/10.1002/app.39297. 